\title{
Slaughtered Cattle as a Source of Rumen Fluid to Evaluate Supplements for In Vitro Degradation of Grass Nuts and Barley Straw
}

\author{
A.S. Chaudhry ${ }^{*}$
}

School of Agriculture, Food and Rural Development, Newcastle University, NE1 7RU, UK

\begin{abstract}
This factorial study examined the potential of slaughtered cattle as a source of rumen fluid (RF) to test the impact of $0,90,180 \mathrm{~g} / \mathrm{kg}$ forage (Amount) of 2 supplements (Low protein of 12\% =LP; high protein of $25 \%=\mathrm{HP}$ ) on in vitro rumen degradation of grass nuts (Grass) and barley straw (Straw) over various times. RF was collected from three slaughtered cattle (Animal) on three separate occasions and buffered under $\mathrm{CO}_{2}$ as inoculum at $39^{\circ} \mathrm{C}$. About $1 \mathrm{~g}$ ground Straw or Grass and each amount of LP or HP were mixed in separate test tubes with $50 \mathrm{ml}$ inoculum under $\mathrm{CO}_{2}$. The tubes fitted with Bunsen valves were incubated at 0-72h after which the contents were washed and dried to estimate dry matter disappearance (DMD). The DMD were statistically analysed for the main effects of Animal, Forage, Supplement, Amount and their interactions at each incubation but not Animal based interactions. The Forage, Amount and Animal effects were significant $(\mathrm{P}<0.01)$ at most incubations whereas Supplement effect was significant at $72 \mathrm{~h}$ only showing greater DMD for HP than LP $(\mathrm{P}<0.05)$. DMD increased with time for all main effects. Grass had greater DMD than Straw at all incubations $(\mathrm{P}<0.001)$. DMD increased $(\mathrm{P}<0.05)$ with time but not at $0 \mathrm{~h}$ with increasing Amount and increased DMD was greater from 0 to $90 \mathrm{~g} / \mathrm{kg}$ than at 90 to $180 \mathrm{~g} / \mathrm{kg}$. The animals differed $(\mathrm{P}<0.05)$ at all but $0 \mathrm{~h}$ showing variable responses with the confounding effect of their gender, age, breed, size and pre-slaughter feeding. Apparently slaughtered cattle can be used to obtain RF to evaluate supplements for in vitro forage degradation. However, the selection of suitable donor animals of similar pre-slaughter characteristics would be critical if in vitro studies involving slaughtered animals are to be used to evaluate feed supplements before their use for grazing ruminants.
\end{abstract}

Keywords: In vitro degradation, slaughtered cattle, rumen fluid, forage, supplement.

\section{INTRODUCTION}

Various in vitro methods have been used as speedy and cheap alternatives to whole animal studies to evaluate feeds for ruminant animals. Some of these methods have used solvents [1,2] or enzymes [3-6] instead of rumen fluid to study kinetics of rumen degradation. However, the validity of these methods depended upon the availability of either in sacco or rumen fluid based in vitro data for making comparisons [7]. Indeed both in sacco and rumen fluid based in vitro methods require the surgically modified animals which is not desirable due to animal welfare issues, cost and legislation. Therefore, it is imperative to find alternatives to surgically modified animals to obtain rumen fluid to study in vitro degradation of ruminant feeds.

Grass, fresh, dried or ensiled, is perhaps the cheapest ruminant feed to supply energy for cattle and sheep in the UK. However, it declines in digestibility as it matures and loses about $20 \%$ of its nutrients during ensiling or hay making and feeding in winter. Consequently, grazing animals try to eat more grass to match their energy and protein needs to maintain health and production. However, it is impossible for these animals to eat more than the physical capacity of their rumens resulting in energy deficits for high performing animals [8-10]. Grass is also low in minerals and so animal production and health could be affected if grass is fed without supplements [11]. Thus, it is essential to find complementary energy and mineral sources to boost grass digestibil-

*Address correspondence to this author at the School of Agriculture, Food and Rural Development, Newcastle University, NE1 7RU, UK; E-mail: a.s.chaudhry@ncl.ac.uk ity and intake to sustain animal health and performance [12] This could be achieved by using molasses [13] or chelated minerals [14] to compensate for the nutrient deficits in forages including grass and straw. Molasses, an inevitable by-product of sugar industry is rich in energy, highly palatable and could be cost-effective if used in ruminant diets. Chelated minerals are more available than their inorganic counterparts for utilisation by ruminants and so are preferred for inclusion into animal diets. A combination of molasses and chelated minerals as feed-blocks could be even more beneficial as a supplement for forage consuming animals $[15,16]$.

This study examined the use of freshly slaughtered cattle as a source of rumen fluid to assess the suitability of two commercial supplements containing sugars, oils, protein and minerals for in vitro degradation of grass nuts and barley straw. These supplements were chosen to test their complementary properties for two forages of contrasting feeding values that could be available to ruminants during various situations in the UK. The ultimate objective of this study was to test if the rumen fluid from slaughtered cattle could be used to evaluate the suitability of various supplements for in vitro rumen degradation of Grass and Straw before their feeding to forage fed ruminants.

\section{MATERIALS AND METHODOLOGY}

\section{Forages and Supplements}

Two forages, winter barley straw variety Regina (Straw) and grass nuts (Grass) were obtained from the Newcastle University's Farm at Cockle Park and two supplements (low crude protein or $\mathrm{CP}$ of $12 \%=\mathrm{LP}$, and high $\mathrm{CP}$ of $25 \%=\mathrm{HP}$ ) 
were obtained from Caltech Ltd, UK. Caltech manufactured these supplements by cooking molasses at around $125^{\circ} \mathrm{C}$ with sources of protein, energy, trace elements, minerals and vitamins to supply $13 \mathrm{MJ}$ ME with 2 different $\mathrm{CP}$ levels $(120=$ Supp $1 \& 250 \mathrm{~g}=$ Supp 2$) / \mathrm{kg}$ DM and various amounts of minerals and vitamins. While Grass and Straw were dried at $70^{\circ} \mathrm{C}$ in an oven, the samples of supplements were freeze dried before first breaking into pieces and then grinding through a $0.8-1 \mathrm{~mm}$ sieve using Cyclotech 1093 sample mill (Tecator Ltd).

\section{Buffer, Rumen Fluid and Microbial Inhibitor}

A buffer of $\mathrm{pH}$ 7-8 was prepared as described by McDoughall [17], saturated with $\mathrm{CO}_{2}$ and stored in a screw capped bottle in a water bath at $39^{\circ} \mathrm{C}$ until required. Rumen contents were collected from three cattle freshly slaughtered at a local abattoir (Whitley Meat Company, Northumberland, UK) on three separate occasions. The contacts of the respective owner farmers were obtained from the abattoir to obtain information about the breed, gender, age, feeding and location of these cattle (Animals) afterwards. About 15 minutes post-slaughter, the rumen of each animal was cut open with a kitchen knife to collect the contents which were immediately strained into pre-warmed thermal flasks through 3 layers of a cheese cloth at each occasion and transported back to the University Laboratory. One portion of the strained rumen fluid (SRF) was then mixed in a dark bottle with 4 portions of the pre-warmed buffer to achieve a ratio of 1:4 between SRF and the buffer (inoculum) [18]. The bottle containing the inoculum was then saturated with $\mathrm{CO}_{2}$, screw capped and kept in a water bath at $39^{\circ} \mathrm{C}$. A $5 \%$ solution of mercuric chloride $\left(\mathrm{HgCl}_{2}\right)$ in distilled water was prepared as a microbial inhibitor to terminate the in vitro incubations at each of the treatment times as detailed below.

\section{Experimental Design}

The study was conducted according to a duplicated $2 \times 2$ x 3 factorial arrangement with three replicates involving 2 forages (Grass and Straw), 2 supplements (LP and HP) each with 3 Levels $(0,9,18 \mathrm{mg} / \mathrm{ml}$ rumen fluid representing 0,90 and $180 \mathrm{~g} / \mathrm{kg}$ forage) for each of the 6 incubation times $(0,6$, $12,24,48,72$ hours). Each replicate was run on a separate occasion by using SRF from different animals slaughtered freshly at the abattoir.

\section{In Vitro Incubations}

About 1g sample of dried ground Grass or Straw was weighed into each glass test tube, with total capacity of $100 \mathrm{ml}$, for each incubation time. LP or HP was then weighed separately into these test tubes to represent the predetermined amounts $(0,90$ and $180 \mathrm{~g} / \mathrm{kg}$ forage $)$ and kept in a water bath at $39^{\circ} \mathrm{C}$. About $50 \mathrm{ml}$ of inoculum was added into each test tube which was then flushed with $\mathrm{CO}_{2}$, capped with a Bunsen valve and incubated at $39^{\circ} \mathrm{C}$ for the above mentioned times. Simultaneous blanks for each supplement only (incubation medium with no forage) and for the medium (no forage and no supplement) were also run for each incubation time in each batch to correct each determination for the presence of soluble components and fine particles in blank inoculums. After each incubation time, the microbial inhibitor was added in relevant tubes to terminate the reac- tion. The undegraded residue from each tube was then collected on a dried pre-weighed filter paper (Whatman No 541) under water suction and washed three times with cold tap water before drying in an oven at $70^{\circ} \mathrm{C}$.

\section{Chemical Analysis}

The fermentation profiles of each RF were determined by using Jenway 3340 meter for $\mathrm{pH}$, an auto-analyser system for ammonia where RF was reacted with nitroprussidehypochlorite reagents and Perkin Elmer AutoSystem gas chromatography for volatile fatty acids (VFA) as described by Rezaeian et al. [19]. The original samples of forages and supplements were analysed for dry matter (DM), organic matter $(\mathrm{OM})$, crude protein $(\mathrm{CP}=\mathrm{Nx} 6.25)$, neutral detergent fibre (NDF) and ether extract (EE or oil) by using standard procedures [20]. However, the residues of each sample after each incubation time were analysed for only DM contents to estimate the disappearance of DM (DMD) from each of the two forages in response to each supplement during various hours of in vitro incubations. Disappearances of other nutrients were not studied as DMD was considered appropriate and indeed a cheaper way to test the concept of using slaughtered animals to evaluate supplements.

\section{Calculations and Statistical Analysis}

The DMD was estimated by subtracting the residual DM after each incubation time from the sum of DM in the corresponding forage and the relevant supplement. The observations were then corrected for the corresponding blanks. No effort was made to fit DMD data into a non linear model to derive estimates of degradation kinetics $(a, b, c$ and $P$ ). Instead, it was considered appropriate to statistically compare the effects of supplements on DMD at each incubation time by using PROC GLM in SAS (1994) [21]. The model included the main effects of cattle (Animal), forage, supplement type and amount (Amount) of each supplement. The effect of 2 and 3 way interactions were also studied. Tukey's test was used to compare differences between means for various treatment effects. However, the animal related interactions were not tested as the Animal effect was studied to establish if these animals were fair representatives of animal variations. Significance was declared at $\mathrm{P}<0.05$ unless otherwise stated.

\section{RESULTS}

\section{General}

Both supplements, LP and HP, were dark brown in colour and had a toffee like sugary smell and a solid block form. The grinding of these products was difficult because of their sticky nature and ability to melt during grinding causing blockage of the sieve pores. They also tended to block the pores of the filter papers being used to separate undegraded residues following in vitro incubations. The problem during grinding was partly tackled by freeze-drying and the pores of the filter papers were unblocked with a plastic spatula during washing with water followed by filtration.

\section{Nutrient Composition}

Table 1 presents nutrient composition of each forage and supplement. Grass contained more CP but less OM and NDF 
than Straw whereas HP contained more OM, CP, EE and NDF than LP.

\section{Characteristics of Slaughtered Cattle and Fermentation Profiles of Rumen Fluids}

Table 2 presents pre slaughter characteristics of cattle and fermentation profiles of their rumen fluids that were used for this in vitro study. It is clear from Table $\mathbf{2}$ that three cattle of this differed widely in terms of their characteristics and feeding routines and therefore represented a range of variations that could occur between animals during animal studies in different situations. The rumen fluid profiles $(\mathrm{pH}$, ammonia and VFA) of these animals were also variable.

\section{Main Effects on Dry Matter Disappearance at Various Times}

Table 3 presents the means for various main effects at different hours of in vitro incubation. The main effects of Forage, Supplement, Amount and Animal were significant $(\mathrm{P}<0.01)$ at most hours whereas the effect of Supplement was only significant at 72 hours of incubation where DMD for $\mathrm{HP}>\mathrm{LP}(\mathrm{P}<0.05)$. In contrast, all 2 and 3 way interactions were non significant. The DMD increased with hours of incubations for all the main factor effects. As expected, Grass had significantly greater DMD than Straw at all incubations
Table 1. Mean ( $n=2)$ Nutrient Composition of Forages and Supplements (g/kg DM)

\begin{tabular}{|l|c|c|c|c|}
\hline \multicolumn{1}{|c|}{ Nutrients } & Grass & Straw & LP & HP \\
\hline \hline Organic matter & 921 & 956 & 735 & 845 \\
\hline Ether extract & 29 & ND & 31 & 79 \\
\hline Crude Protein & 168 & 32 & 118 & 247 \\
\hline Neutral detergent fibre & 606 & 859 & 56 & 68 \\
\hline Calcium & 7 & 2.9 & 40 & 30 \\
\hline Phosphorus & 2.4 & 0.4 & 30 & 15 \\
\hline Magnesium & 2.4 & 0.6 & 10 & 3 \\
\hline Potassium & 16.9 & 7.8 & NA & NA \\
\hline Sodium & 4.8 & 0.4 & NA & NA \\
\hline Chloride & 21.8 & 1.1 & NA & NA \\
\hline Sulphur & 2.6 & 0.6 & NA & NA \\
\hline Copper & 0.015 & 0.05 & 0.5 & 0.6 \\
\hline Manganese & 0.139 & 0.021 & 0.8 & 0.8 \\
\hline Zinc & 0.051 & 0.04 & 1.2 & 0.8 \\
\hline Iodine & 0.01 & 0.01 & 0.08 & 0.08 \\
\hline Cobalt & 0.012 & 0.001 & 0.08 & 0.08 \\
\hline Selenium & Traces & Traces & 0.005 & 0.004 \\
\hline
\end{tabular}

$\mathrm{LP}=$ Low Protein and $\mathrm{HP}=$ high protein supplements; NA= Not available.

Table 2. Pre Slaughter Characteristics and Fermentation Profiles of Rumen Fluid (RF) of Cattle

\begin{tabular}{|c|c|c|c|}
\hline \multirow{2}{*}{ Parameters } & \multicolumn{3}{|c|}{ Cattle (Animal) Identification Number } \\
\hline & 1 & 2 & 3 \\
\hline \multicolumn{4}{|l|}{ Pre slaughter characteristics } \\
\hline Location & Barnsley & Brunswick & Morpeth \\
\hline Feeding (Pre SL) & $\mathrm{H}+\mathrm{F}+\mathrm{WT}$ & $\mathrm{BS}+\mathrm{St}+\mathrm{C}$ & $\mathrm{S}+\mathrm{G}+\mathrm{C}$ \\
\hline Breed & CharX & SimmX & BndX \\
\hline Gender & Male & Male & Female \\
\hline Age in days & 593 & 684 & 533 \\
\hline Carcass wt (kg) & 228 & 316 & 256 \\
\hline RF collection date & 31 October & 13 November & 21 November \\
\hline \multicolumn{4}{|l|}{ Fermentation profiles of RF } \\
\hline $\mathrm{pH}$ & 6.8 & 7.3 & 7.2 \\
\hline Ammonia (mg /L) & 122.5 & 63.1 & 72.2 \\
\hline Total VFA (mmoles /L) & 60.9 & 69.1 & 82.4 \\
\hline \multicolumn{4}{|c|}{ VFA components (mol /100 mol of Total VFA) } \\
\hline Acetetate & 52.96 & 75.66 & 68.35 \\
\hline Propionate & 31.38 & 17.89 & 20.82 \\
\hline Isobutyrate & 2.58 & 0.681 & 0.70 \\
\hline Butyrate & 7.88 & 4.43 & 8.47 \\
\hline Isovalerate & 3.76 & 0.91 & 1.04 \\
\hline Valerate & 1.44 & 0.427 & 0.607 \\
\hline
\end{tabular}

Here $\mathrm{H}+\mathrm{F}+\mathrm{WT}$ was a grass hay or forage based diet plus wheat grain, $\mathrm{BS}+\mathrm{St}+\mathrm{C}$ was a big bale silage plus straw and a concentrate mix and $\mathrm{S}+\mathrm{G}+\mathrm{C}$ was a ryegrass silage plus grazing and $1 \mathrm{~kg}$ commercial feed $/ \mathrm{PM}$; Char X, Simm X and Blnd X were Charolais X, Simmental X and Blonde d'Aquitaine X cattle respectively. All animals were brought to the abattoir where they were fasted overnight on straw bedding before their slaughter next day. 
Table 3. The Means (g/kg), Standard Errors (SE) and Significance for the Main Effects of Forage, Supplement, Amount and Animal at Different Hours (Hrs) of Incubation

\begin{tabular}{|c|c|c|c|c|c|c|c|c|c|c|c|c|c|c|}
\hline \multirow{2}{*}{ Hrs } & \multicolumn{2}{|c|}{ Forage } & \multirow{2}{*}{ SE } & \multicolumn{2}{|c|}{ Supplement } & \multirow{2}{*}{ SE } & \multicolumn{3}{|c|}{ Amount } & \multirow{2}{*}{ SE } & \multicolumn{3}{|c|}{ Animal } & \multirow{2}{*}{ SE } \\
\hline & Grass & Straw & & $\mathbf{L P}$ & HP & & 0 & 90 & 180 & & 1 & 2 & 3 & \\
\hline 0 & 247 & 102 & $14^{* * * *}$ & 177 & 164 & $14^{\mathrm{NS}}$ & $155^{\mathrm{a}}$ & $174^{\mathrm{ab}}$ & $186^{\mathrm{b}}$ & $17^{\mathrm{NS}}$ & 180 & 181 & 158 & $17^{\mathrm{NS}}$ \\
\hline 6 & 276 & 141 & $13^{* * * *}$ & 205 & 207 & $13^{\mathrm{NS}}$ & $171^{\mathrm{a}}$ & $217^{\mathrm{b}}$ & $230^{\mathrm{b}}$ & $16^{*}$ & $218^{\mathrm{a}}$ & $230^{\mathrm{a}}$ & $175^{\mathrm{b}}$ & $16^{*}$ \\
\hline 12 & 309 & 147 & $15^{* * * *}$ & 223 & 235 & $15^{\mathrm{NS}}$ & $192^{\mathrm{a}}$ & $235^{\mathrm{b}}$ & $259^{\mathrm{b}}$ & $18^{* *}$ & $235^{\mathrm{a}}$ & $249^{a}$ & $203^{b}$ & $18^{*}$ \\
\hline 24 & 373 & 167 & $16^{* * * *}$ & 270 & 273 & $16^{\mathrm{NS}}$ & $236^{\mathrm{a}}$ & $282^{\mathrm{b}}$ & $297^{\mathrm{b}}$ & $20^{* *}$ & $312^{\mathrm{a}}$ & $248^{\mathrm{b}}$ & $254^{\mathrm{b}}$ & $20^{* * *}$ \\
\hline 48 & 515 & 276 & $21^{* * * * *}$ & 388 & 406 & $21^{\mathrm{NS}}$ & $359^{\mathrm{a}}$ & $413^{\mathrm{b}}$ & $414^{\mathrm{b}}$ & $20^{*}$ & $470^{\mathrm{a}}$ & $313^{\mathrm{b}}$ & $378^{\mathrm{c}}$ & $20^{* * * *}$ \\
\hline 72 & 596 & 316 & $20^{* * * * *}$ & 445 & 486 & $20^{*}$ & $442^{\mathrm{a}}$ & $470^{\mathrm{b}}$ & $479^{\mathrm{b}}$ & $18^{*}$ & $545^{\mathrm{a}}$ & $364^{\mathrm{b}}$ & $488^{c}$ & $18^{* * * *}$ \\
\hline
\end{tabular}

*,**, *** Represent the significant differences between means for the main effects at $\mathrm{P}<0.05, \mathrm{P}<0.01$ and $\mathrm{P}<0.001$ respectively; NS $=$ non significant; Means for the Amount an Animal effects with different superscripts for each incubation time were significantly different at $\mathrm{P}<0.05$.

$(\mathrm{P}<0.001)$. The DMD was also increased significantly $(\mathrm{P}<0.05)$ at all but $0 \mathrm{~h}$ in response to the increasing amount of supplement from 0 to $180 \mathrm{~g} / \mathrm{kg}$ but the increase was greater when the amount was increased from 0 to $90 \mathrm{~g} / \mathrm{kg}$ compared with that for the further increase from 90 to $180 \mathrm{~g} / \mathrm{kg}$. The Animal effect was variable as the DMD did not differ at $0 \mathrm{~h}$ but showed significant differences $(\mathrm{P}<0.05$ to 0.001$)$ between animals at other hours of incubation. The Animal effect was much greater at 48 and 72 hours of incubation where DMD was greatest for Animal 1 followed by Animals 3 and $2(\mathrm{P}<0.001)$.

\section{Patterns of DMD Following Supplement Addition at} Various Hours of In Vitro Incubation

Fig. (1) presents the effect of LP addition (0, 90 and $180 \mathrm{~g}$ $/ \mathrm{kg}$ forage) on the pattern of mean in vitro DMD $(\mathrm{g} / \mathrm{kg})$ of Grass (1a) and Straw (1b) over various hours of incubation. Addition of LP improved DMD of Grass and Straw at most hours of incubation. While the extent of DMD of Grass varied with time and amount, the DMD of straw increased consistently at most times (except at 48h) with increasing Amount of LP from 0 to $180 \mathrm{~g} \mathrm{BS} / \mathrm{kg}$.

Fig. (2) presents the effect of HP addition (0, 90 and $180 \mathrm{~g} / \mathrm{kg}$ forage) on the pattern of mean DMD of Grass (2a) and Straw (2b) over various hours of incubation. Addition of HP improved DMD of Grass and Straw at most hours of incubation. Although Straw had less DMD than Grass at each time, it responded better in terms of its consistently increased DMD at each time with increased Amount of HP from 0 to $180 \mathrm{~g} / \mathrm{kg}$ forage.

\section{DISCUSSION}

The variability between these donor animals for their preslaughter characteristics and rumen fermentation profiles was expected as these animals came from different farms and so these were the only animals available for slaughtering on different days of RF collections. Despite variations in their breed, location, age and pre-slaughter feeding, the values of $\mathrm{pH}$, ammonia and the VFA of RF from these animals appeared to be within the acceptable levels of rumen fermentation for the forage consuming animals [19]. The similarity between 3 cattle for DMD at 0h, suggests that the buffered rumen fluids from these animals were almost equally (a)

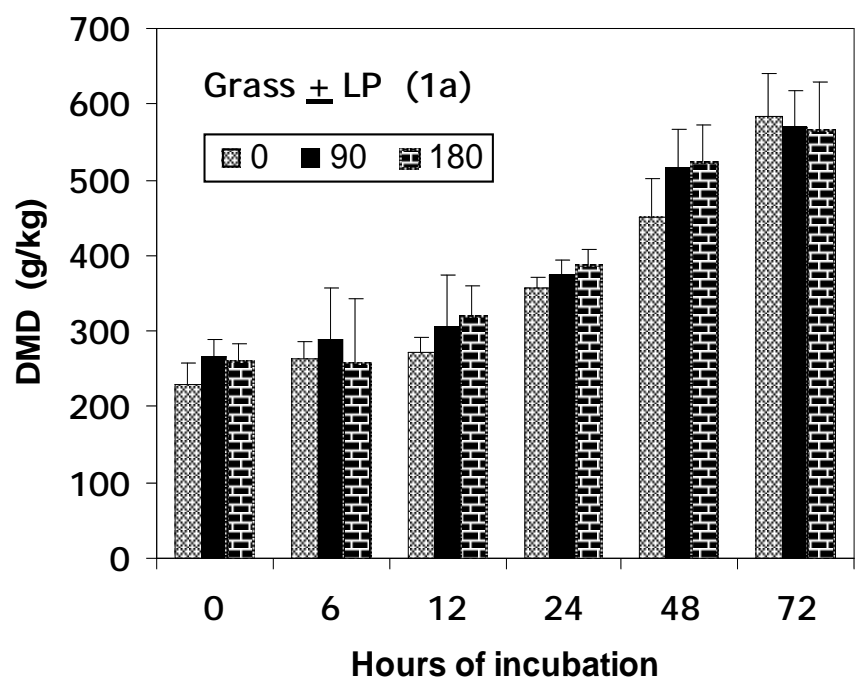

(b)

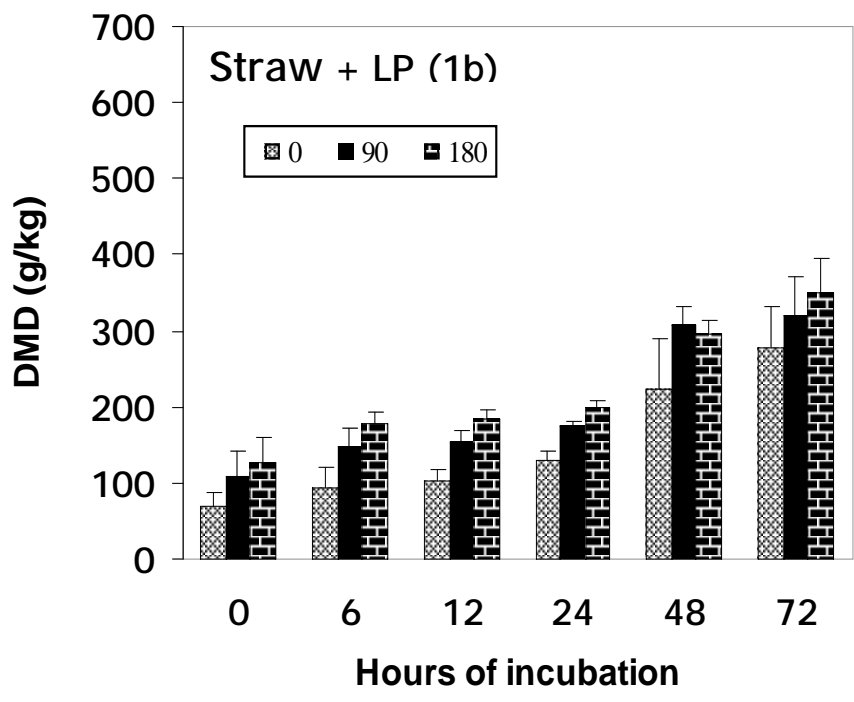

Fig. (1). Effect of adding different amounts $(0,90$ and $180 \mathrm{~g} / \mathrm{kg}$ forage) of Low protein supplement (LP) on the pattern of mean in vitro DMD ( $\mathrm{g} / \mathrm{kg}$ ) of Grass (a) and Straw (b) over various hours of incubation. The $\mathrm{Y}$ bars represent standard errors for each mean. 
(a)

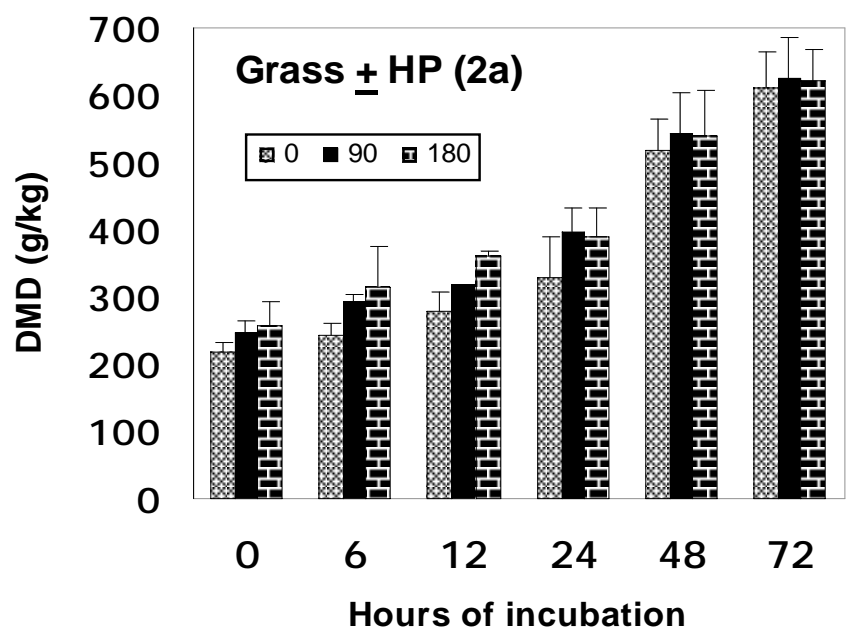

(b)

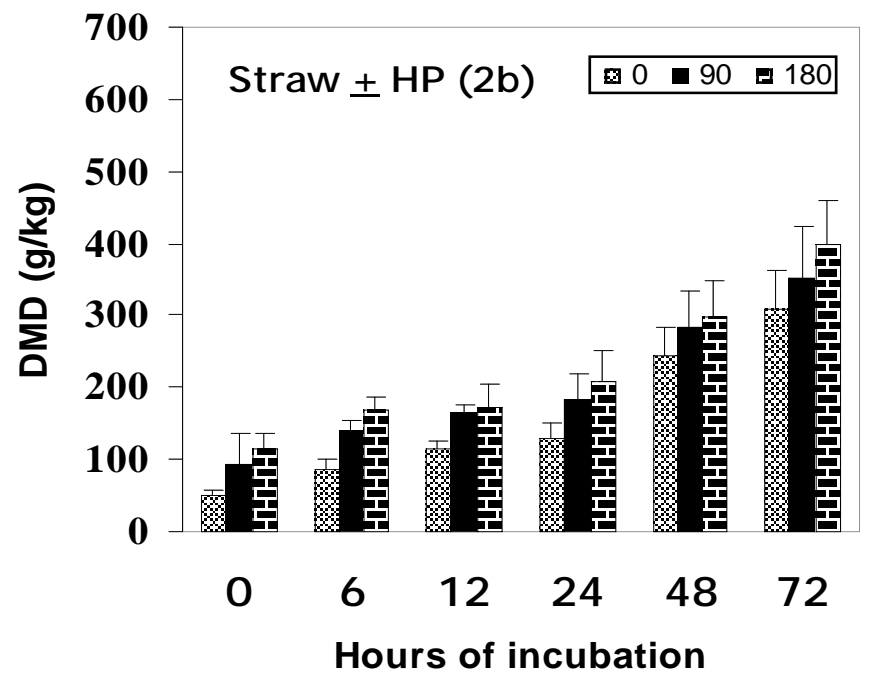

Fig. (2). Effect of adding different amounts (0, 90 and $180 \mathrm{~g} / \mathrm{kg}$ forage) of High protein supplement (HP) on the pattern of mean in vitro DMD ( $\mathrm{g} / \mathrm{kg}$ ) of Grass (a) and Straw (b) over various hours of incubation. The Y bars represent standard errors for each mean.

effective in solubilising forages despite variations in their pre-slaughter characteristics. This feature of buffered rumen fluid was acceptable as the animal variations are expected to affect the microbial activity which did not have enough time to either contribute or interfere instantaneously with the solubility of forages at $0 \mathrm{~h}$ incubations in vitro. Therefore, the similarity in forage DMD at 0 h for rumen fluids from 3 animals was perhaps due to the combined solubility characteristics of grass and straw and not the inherent microbial activity of the rumen fluid. In contrast, the variation in DMD values (Table 3) from $6 \mathrm{~h}$ onwards for 3 animals confirmed that these cattle did represent the wide variations (Table 2) that could occur within animal based in vivo digestibility [22], in sacco degradability [23] and in vitro digestibility [7] data. The variation in DMD can be attributed to the confounding effect of gender, breed, size and pre-slaughter feeding of these cattle as shown in Table 2 [23, 24]. While, it may not be appropriate to apportion these variations by any single feature of these slaughtered cattle, it is interesting to note that the buffered rumen fluid from Animal 1 which con- sumed pre-slaughter a typical hay based diet showed the highest DMD at most times. This suggests that pre-slaughter feeding might have been the major contributor in DMD variations for 3 animals of this study. Therefore, careful selection of animals and particularly pre-slaughter feeding would be required in order to reduce potential variation in rumen fluid for its use to evaluate the suitability of supplements for in vitro DMD of ruminant feeds including forages.

The DMD values of both grass nuts and barley straw in the absence or presence of LP or HP were lower than those that would have been expected by using fistulated animals. However, the extent of differences between un-supplemented Grass and Straw at each incubation time was comparable to those of the published in sacco values for barley straw and dried grass [25]. Even the in vitro DMD (276g/kg in Table 3) of barley straw in this study was comparable to that $(319 \mathrm{~g} / \mathrm{kg})$ of Chaudhry and Miller [26] of a different barley straw sample following 48 hours of incubation with rumen fluid from fistulated sheep. Likewise, the pattern of Straw DMD in vitro over various times in this study was comparable to the pattern of fistulated sheep based in sacco DMD of wheat straw as reported by Chaudhry [27]. Although, the Grass DMD in this study was lower at most times than the fistulated sheep based in sacco DMD of a different sample of the same batch of grass nuts, the overall patterns of in vitro and in sacco DMD for grass nuts were comparable [28]. The lower in vitro $\mathrm{v}$ in sacco values were an indication that the in vitro method was perhaps better in minimising the particle losses for which the in sacco method is mostly criticised [23].

Indeed, the results confirmed that the slaughtered cattle based in vitro study was successful in ranking the effect of various amounts of LP and HP on Grass and Straw at various times. However, Straw appeared to show more consistent increase than Grass in DMD with increasing amount of both supplements at most times. This implies that low quality forages like Straw may benefit more from supplementation with sugars, oils, protein and oils [8, 11, 12]. Likewise, Greenwood et al. [16] found increased rumen fermentation (as indicated by higher ammonia and total volatile fatty acids, VFA) and improved digestion and intake of prairie hay by steers following supplementation with cooked molasses blocks. Although the prairie hay used by Greenwood et al. [16] contained slightly more CP (59 v 32g/kg) and less NDF $(694 \mathrm{v} 859 \mathrm{~g} / \mathrm{kg})$ than Straw of this study, the prairie hay was still regarded as a low quality forage and the similarity between these two forages with supplementation in vivo and in vitro was quite complementary. In contrast, Mbatya et al. [13] did not find any improvement in the intake of urea treated straw by beef cattle with supplementation with molasses at 4 to $12 \%$. This was perhaps due to the absence of other nutrients which were present in supplements of this study and that of Greenwood et al. [16]. This implies that using a balanced form of supplements might be more beneficial than molasses alone. However, it appeared that the incubation time of up to $72 \mathrm{~h}$ was insufficient to achieve a plateau for DMD. This assumption was supported by the shapes of the disappearance patterns for various treatment combinations that did not form the plateau at or before 72 hours of incubation (Figs. 1,2). This implies that incubations beyond $72 \mathrm{~h}$ must be included if forages are to be tested for the in vitro degradation in the future especially if the degradation 
data are used to derive degradation constants for such forages in the future.

The slightly more increase in DMD by HP than LP from $12 \mathrm{~h}$ onwards was perhaps due to the presence of more $\mathrm{CP}$ in HP than LP $(\mathrm{CP}=25 v s 12 \%$, Table 1). The additional supply of CP by HP may have stimulated greater microbial growth to facilitate greater forage degradation during in vitro incubation. However, the extents of increase by HP v LP even at $48 \mathrm{~h}(4 \%)$ or $72 \mathrm{~h}(10 \%)$ of incubations were not proportionate to the extra supply of CP. Therefore, LP should be regarded as equally effective even at relatively lower levels of $\mathrm{CP}$ and oil. These findings are in line with the previous results [16] where similar intake and digestion were observed for prairie hay by rumen fistulated steers consuming supplements from cooked molasses blocks of different ingredient compositions.

The curvilinear increase in DMD with increasing amount of Supplement was perhaps due to the increased stimulation of rumen microbes in response to extra nutrients as supplement during in vitro incubations. However, the reduced overall increase of 5\% in DMD (averaged over all incubation hours) with increasing supplement from 90 to $180 \mathrm{~g} / \mathrm{kg}$ than $18 \%$ at 0 to $90 \mathrm{~g} / \mathrm{kg}$ suggested that the oversupply of nutrients was not beneficial in further improving the DMD. The curvilinear relationships as determined by adding trend-lines to the plots between the amount of Supplement and the mean DMD at each incubation time were excellent as indicated by $\mathrm{R}^{2}$ values of $0.99-1$. However, this does highlight the fact that an increase beyond $90 \mathrm{~g} / \mathrm{kg}$ to supply more sugars and $\mathrm{CP}$ to an in vitro inoculum was unnecessary. Therefore, further studies should fine tune the optimum level of Supplement between 0 to $90 \mathrm{~g} / \mathrm{kg}$. It would also help if the nutrient combinations within Supplement are refined to enhance the degradation of these forages in vitro and the subsequent digestion and intake in vivo.

\section{CONCLUSIONS}

Apparently the slaughtered cattle could be used to obtain rumen fluid to evaluate the suitability of feed supplements in improving forage DMD in vitro. However, more data are needed to validate this statement. Also, careful planning would be needed to minimise potential variations in the composition of rumen fluid due to pre-slaughter type, age and especially diets of donor animals in future studies of this kind. It also appeared that the nutritive value as determined by DMD in vitro of grass nuts and barley straw can be improved by adding supplements. It is possible that improved rumen fermentation as indicated by DMD could stimulate forage intake and hence the performance of forage consuming cattle in the presence of supplements.

\section{ACKNOWLEDGEMENTS}

ASC thanks Caltech Limited for funding and initial discussions, Whitley Meat Company for providing rumen fluid samples and Mr. Mike Hearn for his assistance during laboratory analysis.

\section{REFERENCES}

[1] Crooker BA, Sniffen CJ, Hoover WH, Johnson LL. Solvents for soluble N measurements in feedstuff. J Dairy Sci 1978; 61: 437.
[2] Chaudhry AS, Webster AJF. Nutrient composition and the use of solubility to estimate rumen degradability of food proteins in cattle. J Sc Food Agric 2001; 81: 1077-86.

[3] Krishnamoorthy U, Sniffen CJ, Stern MD, Van Soest PJ. Evaluation of a mathematical model of rumen digestion and an in vitro simulation of rumen proteolysis to estimate the rumen undegraded nitrogen content of feedstuffs. Br J Nutr 1983; 50: 555-68.

[4] Luchini ND, Broderick GA, Comb DK. Characterisation of the proteolytic activity of commercial proteases and strained rumen fluid. J Anim Sci 1996; 74: 685-92.

[5] Chaudhry AS. Comparing two commercial enzymes to estimate in vitro proteolysis of purified and semi purified proteins. J Anim Phys Anim Nutr 2005; 89: 403-12.

[6] Chaudhry AS. Enzymic and in sacco methods to estimate rumen degradation of food protein in cattle. J Sci Food Agric 2007; 26 (14): $2617-24$

[7] Kiltessa S, Flinn PC, Irish GG. Comparison of methods used to predict the in vivo digestibility of feeds in ruminants. Austr J Agric Res 1999; 50: 825-41.

[8] Bowman JGP, Sowell BF. Delivery method and supplement consumption by grazing ruminants: A review J Anim Sci 1997; 75: 543.

[9] Steen RWJ, Robson AE. Effects of forage to concentrate ratios in the diet and protein intake on the performance and carcass composition of beef heifers. J Agric Sci 1995; 125: 125-35.

[10] Peyraud JL, Delaby L. Ideal concentrate feeds for grazing dairy cows responses to supplementation in interaction with grazing management and grass quality. In: (ed) Garnsworthy, P.C. and Wiseman, J Recent Adv Anim Nutr 2001; p203-220. Nottingham University Press, UK.

[11] Bargo F, Mullar LD, Kolver ES, Delahoy JE. Invited review: Production and digestion of supplemented dairy cows on pasture. J Dairy Sci 2003; 86: 1-42.

[12] Caton JS, Dhuyvetter DV. Influence of energy supplementation on grazing ruminants: Requirements and responses. J Anim Sci 1996; 75: 533 .

[13] Mbatya PBA, Kay M, Smart RI, Kennedy S. Methods of improving the utilisation of cereal straw by ruminants. 5 . The effect of molasses and dried grass. Anim Feed Sci Technol 1985; 13: 293-8.

[14] Underwood EJ, Suttle NF. The Mineral Nutrition of Livestock. CAB International, Wallingford, Oxon. 2001.

[15] Boirman JGP, Sowell BF, Paterson JA. Liquid supplementation for ruminants fed low quality forages. Anim Feed Sci Technol 1995; 55: $105-138$

[16] Greenwood RH, Titgemeyer EC, Drouillard JS. Effects of base ingredients in cooked molasses blocks on intake and digestion of praireie hay by beef steers. J Anim Sci 2000; 78: 167-172.

[17] McDougall EI. Studies on ruminant saliva. 1. The composition and output of sheep's saliva. Biochem J 1948; 99-105.

[18] Tilley JMA, Terry RA. A two stage technique for the in vitro digestion of forage crops. Grass Forage Sci 1963; 18: 104-11.

[19] Rezaaian M, Beakes GW, Chaudhry AS. Effect of feeding chopped and pelleted Lucerne on rumen fungal mass, fermentation profiles and in sacco degradation of barley straw in sheep. Anim Feed Sci Technol 2006; 128: 292-306.

[20] AOAC. 1998. Official methods of analysis, $16^{\text {th }}$ edition. Association of Official Analytical Chemists, Arlington, VA, USA.

[21] SAS system. SAS /STAT Software. The SAS institute Inc., SAS Campus Drive, Cary, NC USA 1994.

[22] Madsen J, Hvelplund T. Prediction of in situ protein degradability in the rumen. Results of a European ring test. Livestock Prod Sci 1994; 39: 201-12.

[23] Huntington JA, Givens DI. The in situ technique for studying rumen degradation of feeds. A review of the procedure. Nutr Abstr Rev series B 1995; 65: 63-93.

[24] Huntington JA, Givens DI. Studies on in situ degradation of feeds in the rumen: 1. Effect of species, bag mobility and incubation sequence on dry matter disappearance. Anim Feed Sci Technol 1997; 64: 227-41

[25] AFRC. Energy and protein requirements of ruminants: Protein. An advisory manual prepared by the AFRC technical committee on responses to nutrients. CAB International, Oxford, UK. 1993.

[26] Chaudhry AS, Miller EL. In vitro digestibility of barley and wheat straws treated with hydrogen peroxide, sodium hydroxide and sodium peroxide under various conditions. Anim Feed Sci Technol 1994; 50: 1-15. 
[27] Chaudhry AS. Rumen degradation in sacco in sheep of wheat straw treated with calcium oxide, sodium hydroxide and sodium hydroxide plus hydrogen peroxide. Anim Feed Sci Technol 2000; 83: 31323.
[28] Rezaaian M, Chaudhry AS. Chemical composition and in vitro organic matter degradability of various Iranian forages. Proc $\mathrm{Br}$ Soc Anim Sci 2005; p156. 